\title{
Características dos adolescentes ofensores sexuais e de suas vítimas: um estudo de processos judiciais
}

\section{Characteristics of adolescent sexual offenders and their victims: a study of judicial processes}

\author{
Kárita Rachel Pedroso Bastos ${ }^{a}$ \\ (D) https://orcid.org/0000-0002-7314-4553 \\ E-mail: krbastosळgmail.com
}

Alexandra Manoela Lemes Eusébio ${ }^{b}$

(D) https://orcid.org/0000-0002-8857-6017

E-mail: alexandra_manoelaœoutlook.com

Kethelyn Nayara de Almeida Pereirab

(D) https://orcid.org/0000-0001-8445-3952

E-mail: ketnayarळgmail.com

Thiago Oliveira Souza da Silva ${ }^{b}$

(D) https://orcid.org/0000-0002-8294-6443

E-mail: psi.thiagooliveira®gmail.com

\section{Liana Fortunato Costac}

(D) https://orcid.org/0000-0002-7473-1362

E-mail: lianafळterra.com.br

a Distrito Federal. Secretaria de Estado de Justiça e Cidadania. Brasília, DF, Brasil.

buniversidade de Brasília. Instituto de Psicologia. Brasilia, DF, Brasil. 'Universidade de Brasília. Programa de Pós-Graduação em Psicologia Clínica e Cultura. Brasília, DF, Brasil.

\section{Resumo}

A violência sexual praticada por adolescentes ainda é pouco estudada no Brasil. Conhecer esses sujeitos é fundamental para a compreensão do fenômeno e execução de ações preventivas. Este artigo apresenta características dos adolescentes ofensores sexuais, bem como de suas vítimas e do contexto da violência. Para isso, foram analisados 254 processos judiciais, entre 2013 e 2016, no Distrito Federal, envolvendo 285 ofensores e 291 vítimas. A partir das informações coletadas, elaborou-se um quadro descritivo, cuja análise foi realizada de forma contextualizada e tendo como referência outros importantes estudos na área. Os resultados apontaram a diversidade dos adolescentes ofensores sexuais, porém as informações sobre as famílias foram bastante escassas nos processos. Quanto à idade e à escolaridade, a maior parte cometeu a ofensa com $16 / 17$ anos $(41,4 \%)$ e cursava o ensino fundamental II (29,5\%). Um número significativo de adolescentes tinha envolvimento anterior com a justiça $(24,2 \%)$. Os abusos foram prioritariamente extrafamiliares $(48,5 \%)$, com vítimas do sexo feminino (67,7\%), entre 10 e 14 anos (40,5\%) e conhecidas do ofensor ( $92,2 \%)$. Ressaltase a complexidade dos casos, impossibilitando intervenções padronizadas e descontextualizadas, assim como a importância de conhecer o contexto social e as relações familiares desses sujeitos com vistas a intervenções mais assertivas.

Palavras-chave: Adolescência; Caracterização; Adolescente Ofensor Sexual; Abuso Sexual; Família.

\section{Correspondência}

Kárita Rachel Pedroso Bastos

Rua 12 Sul, lote 5, apto. 1.503, bloco A, Águas Claras. Brasília, DF, Brasil. CEP 71939-000. 


\section{Introdução}

Sexual violence practiced by adolescents is poorly studied in Brazil. It is essential to know these subjects to understand the phenomenon and to develop preventive actions. This article presents characteristics of adolescent sexual offenders, as well as their victims and the context of the offense. To this, 254 lawsuits were analyzed, between 2013 and 2016, in Federal District, involving 285 offenders and 291 victims. From the information collected, a descriptive table was elaborated, whose analysis was carried out in a contextualized manner and with reference to other important studies in the area. The results pointed to the diversity of adolescent sexual offenders, but information about families were scarce in the lawsuits. Most of them committed the offense with 16/17 years old (41.4\%) and were in Middle School equivalent -6 th to 8 th grade (29.5\%). A significant number of adolescents had previous involvement with the courts (24.2\%). The abuses were primarily extrafamilial (48.5\%), with female victims (67.7\%), between 10 and 14 years old (40.5\%) and known to the offender (92.2\%). The complexity of the cases is highlighted, making standardized interventions impossible, as well as the importance of knowing the social context of adolescents and their family relationships to more assertive interventions. Keywords: Adolescence; Characterization; Sex Offender Adolescent; Sexual Abuse; Family.
Este texto tem como objetivo apresentar características de adolescentes acusados de cometerem violência sexual, bem como de suas vítimas e do contexto em que ocorreu a violência. Para isso, realizou-se uma pesquisa documental a processos judiciais de adolescentes denunciados formalmente, no período de 2013 a 2016, no Distrito Federal, e que, portanto, foram investigados por parte do sistema de Justiça.

A violência sexual não é algo recente na história, mas atualmente é considerada um grande problema de saúde pública, devido à elevada incidência epidemiológica e aos graves prejuízos ocasionados no desenvolvimento psicológico, emocional e social das vítimas (Krell; Amador, 2015). Atenta aos diversos agravos causados por esse tipo de violência e às transformações societárias ao longo dos anos, a legislação brasileira também vem ampliando o entendimento no que se refere aos crimes sexuais e enrijecendo as penas. Atualmente, o artigo 213 do Código Penal, alterado pela Lei 12.015/2009, considera estupro o ato de "constranger alguém, mediante violência ou grave ameaça, a ter conjunção carnal ou a praticar ou permitir que com ele se pratique outro ato libidinoso", e o artigo 217-A considera estupro de vulnerável "ter conjunção carnal ou praticar ato libidinoso com menor de 14 anos". Ainda como estupro de vulnerável, o parágrafo primeiro do artigo 217-A diz que "incorre na mesma pena quem pratica ações descritas no caput com alguém que, por enfermidade ou deficiência mental, não tem o necessário discernimento para a prática do ato, ou que, por qualquer outra causa, não pode oferecer resistência" (Brasil, 2009).

Recentemente, a Lei 13.718/2018 também alterou os artigos 215-A e 218-C do Código Penal, tipificando como crime a importunação sexual, considerada como "praticar contra alguém e sem a sua anuência ato libidinoso com o objetivo de satisfazer a própria lascívia ou a de terceiro", e a oferta, troca, publicação, divulgação, inclusive nos meios de comunicação, de cenas de estupro ou estupro de vulnerável, ou que induza a sua prática, bem como cenas de sexo, nudez ou pornografia sem o consentimento da vítima (Brasil, 2018a). Dessa forma, considera-se violência 
sexual/abuso sexual qualquer ato ou conduta que vise à satisfação sexual de um adulto ou adolescente com uma diferença de idade significativa da vítima, podendo ou não incluir contato físico e penetração. Importante destacar que nos casos de abuso sexual infanto-juvenil há uma relação de hierarquia e poder sobre as vítimas, que estão em desenvolvimento cognitivo e físico e possuem nível de maturidade inferior ao do ofensor (Said; Costa, 2019).

$\mathrm{Na}$ literatura internacional, especialmente nos países de língua inglesa, o termo "ofensa sexual" vem sendo utilizado de forma equivalente a "abuso sexual”, porém voltado especialmente para a pessoa que praticou o ato, ou seja, o ofensor, adulto ou adolescente, que tenha sido julgado e condenado por esse tipo de violência (Domingues; Costa, 2017). Nesse sentido, ao fazer referência ao adolescente julgado por cometer violência sexual/abuso sexual, priorizou-se, neste artigo, o termo "adolescente ofensor sexual".

Mediante a legislação brasileira, não só os adultos respondem pelos crimes sexuais, mas também os adolescentes que cometem abuso sexual devem ser responsabilizados, uma vez que nos casos de comprovação da prática de ato infracional (ato correspondente à conduta descrita como crime ou contravenção penal), o Estatuto da Criança e do Adolescente estabelece a aplicação de medidas socioeducativas, que vão da advertência à internação (Brasil, 1990). No Brasil, poucos são os estudos sobre adolescentes ofensores sexuais, tanto no que se refere à sistematização de dados estatísticos quanto sobre as suas características e trajetória de vida (Costa et al., 2013; Pincolini; Hutz, 2014). Costa e Santos (2013) destacam que, apesar da responsabilização do autor da violência sexual se apresentar como uma importante forma de controle social, somente mantê-lo preso não é suficiente para prevenir uma nova recidiva. Em geral, o ofensor sexual precisa de tratamento e acompanhamento. Assim, tanto para os ofensores adultos quanto para os ofensores adolescentes é fundamental conhecer o contexto em que vivem e suas relações familiares.

Para Carreteiro (2010), a adolescência deve ser considerada em sua multiplicidade, uma vez que não existe uma adolescência única, mas sim "adolescências". É uma fase de muitas transformações, sejam elas biológicas, hormonais, sociais, emocionais e inter-relacionais. Por um lado, é um período propenso à vivência de crises, marcado pelo movimento de ruptura com a infância e pela busca de um novo status (Lara; Abdo, 2015). Por outro, é também um período rico de possibilidades, descobertas e mudanças, visto que é nessa etapa que o ser humano sofre as maiores modificações no seu processo vital e experimenta diversos papéis e situações sociais (Penso et al., 2012).

Do ponto de vista psicossexual, com a chegada da puberdade, o adolescente passa a experimentar modificações intensas no corpo e, consequentemente, fortes mudanças em outros aspectos da vida, que não acontecem sem angústias nem conflitos. Ocorrem transformações no modo em que ele se vê diante do mundo, no seu modo de sentir, de vivenciar emoções e sentimentos. Como essa maturação sexual tem ocorrido cada vez mais cedo, muitas vezes não coincide com o desenvolvimento cognitivo e emocional, aumentando as chances de uma iniciação sexual prematura. A falta de comunicação dentro das famílias a respeito da sexualidade agrava tal elemento, já que é escasso um diálogo aberto e seguro sobre o assunto. Todo jovem vive experimentações nessa fase, que podem ser "ensaísticas" ou "definitivas", e nesse contexto de mudanças, os modos de ser e de viver do adolescente têm estreita relação com os contextos familiares, sociais e culturais (Carreteiro, 2010). Para além dos fatores biológicos, o contexto familiar e o grupo de pares, assim como a cultura juvenil, têm uma influência fundamental nos comportamentos sexuais e na experimentação de afeto e intimidade na adolescência (Barroso, 2012).

Em países como Estados Unidos e Canadá, os estudos sobre violência sexual cometida por adolescentes estão bem mais avançados em relação à identificação e caracterização de seus autores. Worling e Langton (2015) apontam que a violência sexual, nesses países, vem sendo cometida cada vez mais por adolescentes. Na América do Norte, entre $14 \%$ e $18 \%$ das prisões por ofensa sexual são cometidas por jovens abaixo de 18 anos (Pullman et al., 2014). Especificamente nos Estados Unidos, dos adolescentes com idades entre 12 e 17 anos, $33 \%$ já foram vítimas de violência sexual e $20 \%$ 
foram identificados como ofensores sexuais. Aproximadamente $50 \%$ dos perpetradores de violência sexual referiram que os primeiros atos de agressão sexual contra mulheres começaram na adolescência (Pullman; Seto, 2012). Devido ao aumento de jovens ofensores sexuais, muitas políticas públicas têm sido implantadas, com o objetivo de reduzir tais estatísticas (Pullman et al., 2014).

No Brasil, os dados do Atlas da Violência elaborado pelo Instituto de Pesquisas Econômicas e Aplicadas (Ipea) apontam que em 2016 as delegacias brasileiras registraram 49.497 casos de estupro e o Sistema Único de Saúde (SUS) 22.918 incidentes dessa natureza. Apesar dos dados do Sistema de Informação de Agravos de Notificação do SUS serem aproximadamente metade daqueles registrados nas delegacias, entre os anos de 2011 e 2016, observou-se um aumento de 90,2\% das notificações de estupro (Ipea, 2018). Além disso, pode-se considerar que as duas bases de informações ainda possuem uma grande subnotificação e não dão conta da dimensão real do problema. Tal subnotificação deve-se em grande parte aos sentimentos de vergonha, medo e tolerância da vítima, o medo de dissolução da família, da insistência dos tribunais por regras estritas de evidência, receio dos vários questionamentos e interrogatórios ao longo do processo judicial, além da existência de tabus culturais, favorecendo a manutenção da violência em segredo por anos (Arpini; Savegnago; Witt, 2017; Martins; Jorge, 2010).

Uma importante pesquisa desenvolvida por Pincolini e Hutz (2014) investigou o abuso sexual perpetrado por adultos e adolescentes encaminhados à 1. ${ }^{\text {a e 2. }}{ }^{\mathrm{a}}$ Vara da Infância e Juventude de Porto Alegre entre 2003 e 2007. Os dados mostraram que dos 255 ofensores identificados, 70 eram adolescentes, todos do sexo masculino, com idade média inferior a 15 anos de idade. Em relação à escolaridade, $43 \%$ dos adolescentes estavam entre a $5 .{ }^{a}$ e $6{ }^{a}$ série, e $8,3 \%$ trabalhavam irregularmente. Entre os processos analisados, daqueles referentes aos adolescentes, $70 \%$ consistiam em abuso sexual extrafamiliar e $10 \%$ foram praticados por mais de um adolescente.

Outro recente estudo brasileiro traz um breve perfil dos adolescentes que cometeram ofensa sexual no Distrito Federal. Ao analisar 15 processos judiciais de violência sexual, instaurados entre 2008 e 2013,
Domingues e Costa (2017) identificaram a prevalência dos abusos sexuais no contexto extrafamiliar $(n=10)$, com vítimas, em sua maioria, do sexo feminino e conhecidas do ofensor. Quanto à faixa etária, os ofensores tinham idade entre 12 e 14 anos $(n=4)$ e 15 e 17 anos $(n=11)$. Pôde-se constatar que história pregressa, relação com familiares e redes sociais são inexistentes nos processos, de forma que é levado em conta principalmente informações sobre a vítima.

Estudos sobre adolescentes ofensores sexuais e suas relações familiares destacam que não há um perfil único, tratando-se de um público bastante heterogêneo (Barroso, 2012; Costa; Costa, 2013; Pullman et al., 2014). Embora não se possa generalizar, algumas características comuns são identificadas, como o fato desses adolescentes viverem em ambientes familiares repletos de conflitos e violências (Barroso, 2012; McCuish; Lussier; Corrado, 2014).

Neste sentido, é fundamental interpretar as características dos adolescentes ofensores sexuais, levando em consideração o tipo da amostra (por exemplo, se clínica ou jurídica), a natureza do grupo de estudo (se as vítimas foram crianças), o tipo de comparação do grupo (violentos e não violentos) e o tempo da investigação (se antes ou depois de algum tratamento) (Driemeyer; Yoon; Briken, 2011). O conhecimento mais aprofundado da realidade desses adolescentes tem implicações clínicas tanto para avaliações quanto para intervenções por parte dos programas preventivos (Cale et al., 2015; McCuish; Lussier; Corrado, 2014; Ronis; Borduin, 2007). Diante disso, este estudo pretende ampliar o conhecimento produzido sobre a temática no Brasil, colocando-se ao lado desses outros trabalhos, nacionais e internacionais, que vêm elucidando esses sujeitos e ressaltando a importância de um maior aprofundamento sobre eles para intervenções e ações preventivas mais eficazes.

\section{Método}

Para atingir os objetivos propostos, foram analisados os processos judiciais de adolescentes, do sexo masculino, denunciados por cometerem estupro, no Distrito Federal entre os anos de 2013 a 2016. Adefinição do período a ser estudado teve como motivação dar 
continuidade ao estudo realizado por Domingues e Costa (2017). Assim, o contexto da pesquisa é o da violência sexual perpetrada especificamente por adolescentes e o decorrente processo de responsabilização. Tal contexto envolve diversos atores, entre eles o Sistema de Justiça, incluindo as Varas da Infância e Juventude, os Conselhos Tutelares e as Delegacias da Criança e do Adolescente.

No Distrito Federal existem duas varas responsáveis pela apuração dos atos infracionais infanto-juvenis, que se dividem conforme a área de jurisdição: a Vara da Infância e da Juventude (VIJ) e a Vara Regional de Atos Infracionais da Infância e da Juventude (VRAIJ). Ao receber e investigar as denúncias, as Delegacias da Criança e do Adolescente (DCA) do Distrito Federal encaminham os casos para a VIJ ou VRAIJ, conforme a área de jurisdição, ou nos casos de apreensão em flagrante, o adolescente é encaminhado a um Núcleo de Atendimento Integrado, e posteriormente o processo iniciado ali é conduzido à VIJ ou à VRAIJ para prosseguimento. A seleção e análise dos processos ocorreram junto a essas duas varas.

\section{Seleção dos processos}

As primeiras articulações com as VIJ e VRAIJ aconteceram em março de 2017, quando foi possível identificar que ambas realizam a apuração dos atos infracionais de forma independente e não possuem um sistema de informação único capaz de realizar um levantamento dos adolescentes conforme o ato infracional cometido em todo Distrito Federal. Para isso, a própria VIJ solicitou à DCA uma relação dos boletins de ocorrência decorrentes de violência sexual perpetrada por adolescentes de janeiro de 2013 a dezembro de 2016. A partir desse levantamento, buscou-se nominalmente todos os envolvidos no sistema de informação da VIJ. A relação enviada pela Delegacia identificou 240 adolescentes acusados de cometer algum tipo de violência sexual em todo o Distrito Federal. Destes, 126 advinham da área de jurisdição da VIJ, sendo que só foram encontrados processos judiciais de 95. Já na VRAIJ, o levantamento aconteceu por meio do Núcleo de Estatística do órgão, que encontrou 297 processos referentes a estupro de vulnerável e atentado violento ao pudor, sob a sua jurisdição. Ao todo foram então identificados 392 processos judiciais para análise.
Foram incluídos como critério de inclusão os processos já encerrados (sentenciados), cuja comunicação aos órgãos competentes ocorreu entre janeiro de 2013 a dezembro de 2016, com ofensores precisamente entre 12 e 17 anos, do sexo masculino, acusados formalmente de cometerem ato infracional relativo a estupro. Foram excluídos os processos que não tinham sido concluídos, com ofensores do sexo feminino, com data de comunicação aos órgãos competentes fora do período definido; os processos que não tinham identificação do ofensor ou com ofensor menor de 12 anos; e os processos duplicados. Por fim, para a análise documental, permaneceram 254 processos (175 advindos da VRAIJ e 79 da VIJ), envolvendo 285 adolescentes e 291 vítimas, uma vez que existiam processos cuja violência sexual foi cometida por mais de um adolescente ou com mais de uma vítima. Ressalta-se, assim, que o universo estudado é decorrente de um contexto jurídico, no qual os adolescentes foram investigados e receberam uma resposta do sistema de Justiça, seja a responsabilização, a absolvição ou o arquivamento do processo devido à falta de provas.

\section{Instrumento}

Para registro das informações, foi elaborado antecipadamente um instrumento específico, contendo questões relativas ao processo (período de apuração, sentença, aplicação de medida protetiva e/ou socioeducativa), às características do adolescente acusado e da família (idade na data do fato, atos infracionais/processos anteriores, local de moradia, escolaridade, número de membros na família, responsável, renda familiar, participação em programas socioassistenciais), da vítima (idade na data do fato, sexo, relacionamento com o ofensor) e do abuso sexual (se praticado de maneira individual ou coletiva, intrafamiliar ou extrafamiliar). A partir dos objetivos da pesquisa, a escolha dessas questões baseou-se nos estudos de Pincolini e Hutz (2014) e Domingues e Costa (2017). Especialmente com relação aos adolescentes acusados, um fator limitante no preenchimento do instrumento foi a impossibilidade de obter todas as informações previstas, uma vez que muitas delas não estavam registradas nos processos judiciais. 


\section{Procedimento}

Finalizada a etapa inicial de identificação dos adolescentes, o estudo detalhado do processo (geralmente contendo boletim de ocorrência, folha de passagens criminais, autos de apreensão, despachos e sentenças do juiz, relatórios técnicos, entre outros) ocorreu em salas disponibilizadas pelas VIJ e VRAIJ nos próprios órgãos, durante os meses de setembro de 2017 a junho de 2018. As informações relativas ao perfil do adolescente, da vítima e do processo de responsabilização foram registradas manualmente pelos autores no instrumento específico. Posteriormente, todas as informações foram organizadas em um banco de dados, sendo as análises estatísticas de frequência efetuadas através do programa de informática IBM SPSS Statistics, versão 24.

\section{Cuidados éticos}

O projeto de pesquisa foi autorizado antecipadamente pelos juízes da Vara da Infância e da Juventude do Distrito Federal e da Vara Regional de Atos Infracionais da Infância e da Juventude do Distrito Federal, sendo ainda aprovado pelo Comitê de Ética do Instituto de Ciências Humanas e Sociais da Universidade de Brasília, conforme parecer $\mathrm{n}^{\mathrm{0}}$ 2.054.880.

\section{Resultados}

Apresenta-se neste texto um recorte das informações registradas e analisadas, especialmente aquelas relacionadas à caracterização do adolescente ofensor sexual e de suas vítimas. Os resultados estão organizados em duas seções. A primeira se refere às principais características dos adolescentes acusados e de suas famílias. A segunda trata especificamente das vítimas e contexto da ofensa sexual.

\section{Características dos adolescentes ofensores sexuais}

Foram coletadas informações de 285 adolescentes denunciados e processados judicialmente por cometerem ofensa sexual. A Tabela 1 apresenta os resultados referentes às informações do adolescente e sua família.

\section{Tabela I - Características dos adolescentes processados por abuso sexual, segundo a idade}

\begin{tabular}{|c|c|c|c|c|}
\hline \multirow{3}{*}{ Caracteristicas } & \multicolumn{4}{|c|}{ Idade ${ }^{(1)}$} \\
\hline & $12 / 13$ & $14 / 15$ & $16 / 17$ & Total \\
\hline & $n(\%)$ & $n(\%)$ & $n(\%)$ & $n(\%)$ \\
\hline \multicolumn{5}{|l|}{ Escolaridade } \\
\hline Fundamental I (2) & $6(2,1 \%)$ & $10(3,5 \%)$ & $2(2,1 \%)$ & $22(7,7 \%)$ \\
\hline Fundamental II ${ }^{(3)}$ & $19(6,9 \%)$ & $37(13 \%)$ & $28(9,8 \%)$ & $84(29,5 \%)$ \\
\hline EM Incompleto ${ }^{(4)}$ & $1(0,4 \%)$ & $6(2,1 \%)$ & $21(7,4 \%)$ & $28(9,8 \%)$ \\
\hline EM Completo ${ }^{(5)}$ & 0 & 0 & $3(1,1 \%)$ & $3(1,1 \%)$ \\
\hline N.I. ${ }^{(6)}$ & $33(11,6 \%)$ & $55(19,3 \%)$ & $60(21,1 \%)$ & $148(51,9 \%)$ \\
\hline \multicolumn{5}{|l|}{ Prática do abuso } \\
\hline Coletivo & $17(6,0 \%)$ & $22(7,7 \%)$ & $29(10,2 \%)$ & $68(23,9 \%)$ \\
\hline Individual & $42(14,7 \%)$ & $86(30,2 \%)$ & $89(31,2 \%)$ & $217(76,1 \%)$ \\
\hline \multicolumn{5}{|c|}{ Envolvimento anterior com a justiça } \\
\hline Sim & $8(2,8 \%)$ & $25(8,8 \%)$ & $36(12,6 \%)$ & $69(24,2 \%)$ \\
\hline Não & $49(17,2 \%)$ & $83(29,1 \%)$ & $76(26,7 \%)$ & $208(73,0 \%)$ \\
\hline N.I. & $2(0,7 \%)$ & 0 & $6(2,1 \%)$ & $8(2,8 \%)$ \\
\hline \multicolumn{5}{|c|}{ No de pessoas na familia } \\
\hline Até 02 & $1(0,4 \%)$ & $2(0,7 \%)$ & $6(2,1 \%)$ & $9(3,2 \%)$ \\
\hline $3 \times 4$ & $13(4,6 \%)$ & $30(10,5 \%)$ & $21(7,4 \%)$ & $64(22,5 \%)$ \\
\hline 5 a 6 & $6(2,1 \%)$ & $16(5,6 \%)$ & $9(3,2 \%)$ & $31(10,9 \%)$ \\
\hline $7 \mathrm{ou}+$ & $3(1,1 \%)$ & $3(1,1 \%)$ & $4(1,4 \%)$ & $10(3,5 \%)$ \\
\hline Abrigo & $5(1,8 \%)$ & $4(1,4 \%)$ & $4(1,4 \%)$ & $13(4,6 \%)$ \\
\hline N.I. & $31(10,9 \%)$ & $53(18,6 \%)$ & $74(26,0 \%)$ & $158(55,4 \%)$ \\
\hline
\end{tabular}




\section{Tabela I-Continuação}

\begin{tabular}{|c|c|c|c|c|}
\hline \multirow{3}{*}{ Características } & \multicolumn{4}{|c|}{ Idade (1) } \\
\hline & $12 / 13$ & $14 / 15$ & $16 / 17$ & Total \\
\hline & $n(\%)$ & $n(\%)$ & $n(\%)$ & $n(\%)$ \\
\hline \multicolumn{5}{|l|}{ Renda familiar $(\mathrm{Sm})^{(7)}$} \\
\hline Menos de I & $2(0,7 \%)$ & $2(0,7 \%)$ & 0 & $4(1,4 \%)$ \\
\hline 122 & $2(0,7 \%)$ & $10(3,5 \%)$ & $6(2,1 \%)$ & $18(6,3 \%)$ \\
\hline $3 a 4$ & 0 & 0 & $3(1,1 \%)$ & $3(1,1 \%)$ \\
\hline Mais de 4 & $1(0,4 \%)$ & $4(1,4 \%)$ & $1(0,4 \%)$ & $6(2,1 \%)$ \\
\hline Abrigo & $5(1,8 \%)$ & $4(1,4 \%)$ & $4(1,4 \%)$ & $13(4,6 \%)$ \\
\hline N.I. & $49(17,2 \%)$ & $88(30,9 \%)$ & $104(36,5 \%)$ & $241(84,6 \%)$ \\
\hline Total de adolescentes processados & $59(20,7 \%)$ & $108(37,9 \%)$ & $118(41,4 \%)$ & $285(100 \%)$ \\
\hline
\end{tabular}

${ }^{(1)}$ Idade do adolescente na data do fato; ${ }^{(2)}$ Fundamental I: I ao 5 ano; ${ }^{(3)}$ Fundamental II: 6 ao 9 ano; ${ }^{(4)}$ EM Incompleto: ensino médio incompleto; ${ }^{(5)}$ EM Completo: ensino médio completo; ${ }^{(6)}$ N.I.: não informado ou não identificado; ${ }^{(7)}$ Renda familiar expressa em salário mínimo (Sm).

\section{Características das vítimas}

A Tabela 2 apresenta as informações referentes a 291 vítimas e ao contexto em que o abuso foi praticado.

\section{Tabela 2 - Características das vítimas e tipo de abuso, segundo sexo}

\begin{tabular}{|c|c|c|c|}
\hline \multirow{2}{*}{ Características } & \multicolumn{3}{|c|}{ Sexo } \\
\hline & $\begin{array}{l}\text { Feminino } \\
n(\%)\end{array}$ & $\begin{array}{l}\text { Masculino } \\
\mathrm{n}(\%)\end{array}$ & $\begin{array}{l}\text { Total } \\
n(\%)\end{array}$ \\
\hline \multicolumn{4}{|l|}{ Idade } \\
\hline o 24 & $25(8,6 \%)$ & $16(5,5 \%)$ & $41(14,1 \%)$ \\
\hline 5 a 9 & $40(13,7 \%)$ & $65(22,3 \%)$ & $105(36,1 \%)$ \\
\hline $10 \mathrm{a} 14$ & $106(36,4 \%)$ & $12(4,1 \%)$ & $118(40,5 \%)$ \\
\hline 15 a 19 & $12(4,1 \%)$ & $\mathrm{I}(0,3 \%)$ & $13(4,5 \%)$ \\
\hline 20 ou mais & $13(4,5 \%)$ & 0 & $13(4,5 \%)$ \\
\hline N.I. ${ }^{(1)}$ & 1 & 0 & $\mathrm{I}(0,3 \%)$ \\
\hline \multicolumn{4}{|l|}{ Tipo de abuso } \\
\hline Extrafamiliar & $110(37,8 \%)$ & $31(10,7 \%)$ & $141(48,5 \%)$ \\
\hline Intrafamiliar & $78(26,8 \%)$ & $56(19,2 \%)$ & $134(46,0 \%)$ \\
\hline Institucional (2) & $8(3,1 \%)$ & $7(2,1 \%)$ & $15(5,2 \%)$ \\
\hline N.I. & $1(0,3 \%)$ & 0 & I (0,3\%) \\
\hline \multicolumn{4}{|l|}{ Vínculo vitima-ofensor } \\
\hline Desconhecidos & $21(7,2 \%)$ & $\mathrm{I}(0,3 \%)$ & $22(7,5 \%)$ \\
\hline Conhecidos/Vizinhos & $29(10,0 \%)$ & $26(8,9 \%)$ & $55(18,9 \%)$ \\
\hline Irmãos & $29(10 \%)$ & $19(6,5 \%)$ & $48(16,5 \%)$ \\
\hline Primos & $33(11,3 \%)$ & $34(11,7 \%)$ & $67(23 \%)$ \\
\hline $\begin{array}{l}\text { Parentes } \\
\text { Sobrinhos }\end{array}$ & $14(4,8 \%)$ & $3(1 \%)$ & $17(5,8 \%)$ \\
\hline Outros parentes ${ }^{(3)}$ & $4(1,4 \%)$ & 0 & $4(1,4 \%)$ \\
\hline Amigos/Colegas/ & $66(22,7 \%)$ & $11(3,8 \%)$ & $77(26,5 \%)$ \\
\hline \multicolumn{4}{|l|}{ Namorados } \\
\hline N.I. & $1(0,3 \%)$ & 0 & $1(0,3 \%)$ \\
\hline Total Vítimas & $197(67,7 \%)$ & $94(32,3 \%)$ & $291(100 \%)$ \\
\hline
\end{tabular}

${ }^{(1)}$ N.I.: não informado ou não identificado; ${ }^{(2)}$ Considera-se abuso institucional aquele cometido em instituições de acolhimento; ${ }^{(3)}$ Outros parentes: esposa $(n=1)$; mãe $(n=1)$; avó $(n=1)$; cunhada $(n=1)$.

\section{Discussão dos resultados}

Os resultados apontam a diversidade de adolescentes acusados de cometerem abuso sexual, conforme já relatado em pesquisas nacionais e internacionais (Cale et al., 2015; Domingues; Costa, 2017; McCuish; Lussier; Corrado, 2014; Pullman et al., 2014). Apesar de a maioria deles estar com 16/17 anos (41,4\%), nos anos finais da adolescência, também significativa foi a faixa etária entre 14/15 anos (37,9\%). Em relação à escolaridade, $29,5 \%$ cursava o ensino fundamental II ( $6^{\circ}$ ao $9^{\circ}$ ano), seguido de $9,8 \%$ com o ensino médio incompleto. Importante destacar que em $51,9 \%$ dos casos não foi possível saber o nível de escolaridade dos adolescentes.

Em relação à família, as informações foram bastante escassas. As famílias de 6,3\% dos adolescentes tinham renda familiar entre um e dois salários-mínimos na época do fato e 22,5\% dos adolescentes tinham famílias compostas por três a quatro membros. Apesar disso, não foi possível identificar a composição familiar em 55,4\% dos casos e a renda familiar em $84,6 \%$, demonstrando um desconhecimento do sistema de Justiça quanto às famílias dos acusados. Outras informações como pessoa responsável pelo adolescente, inclusão em programas sociais também estavam previstas no instrumento de coleta de dados, porém devido à falta ou inconsistência das informações, preferiu-se não incluir no estudo. Tais informações são importantes uma vez que fornecem elementos significativos em relação ao contexto social em que vive o adolescente. Constatou-se que o sistema de Justiça pouco sabe a 
respeito da configuração e situação socioeconômica familiar ao apurar um ato infracional.

Costa e Costa (2013) ressaltam que a violência sexual produz um conjunto de implicações e consequências que confundem os limites intergeracionais e consequentemente a representação social dos papéis de adulto, família, pai, tio e irmão. Em relação às famílias de adolescentes que cometeram abuso sexual, uma característica marcante é o apoio familiar e social restrito, visto que essas famílias não convivem com outros parentes distantes, limitando as trocas afetivas, e não fazem uso dos recursos sociais da comunidade. Além disso, são adolescentes que possuem poucos amigos, estão numa situação de isolamento social, relacionam-se mais com crianças pequenas e vivenciam sentimentos de inadequação social e sexual, rejeição e submissão (Costa; Costa, 2013). Suas famílias se voltam especialmente para a manutenção das necessidades básicas, com distribuição de tarefas e responsabilidades entre os seus membros, ficando o adolescente ofensor, na maioria das vezes, responsável pelo cuidado da casa e dos irmãos enquanto os pais trabalham fora (Costa et al., 2013). Barroso (2012) relata ainda que os ofensores sexuais apresentam mais história de abuso sexual, físico e negligência, assim como exposição precoce a sexo e pornografia, manifestam mais interesses sexuais atípicos, são mais ansiosos e com baixa autoestima. Dessa forma, informações sobre escolaridade, convivência com pares, contexto social do adolescente e de sua família são muito relevantes, pois direcionam os encaminhamentos e intervenções preventivas.

Em relação à prática do abuso sexual, a pesquisa identificou um número significativo de casos cometidos com a presença de mais de um adolescente ofensor (23,9\%), principalmente com idades entre 16 e 17 anos (10,2\%). Segundo o Atlas da Violência, de 2011 a 2016, houve acréscimo de casos de estupros coletivos, passando de 13\% para 15,4\% (Ipea, 2018). Nesses casos, a maior proporção das vítimas é de adolescentes ou pessoas maiores de 18 anos. Sobre isso, o estudo de Santos et al. (2015), com agressores sexuais de uma cidade no Nordeste do Brasil (adolescentes e adultos), apontou que 13,6\% dos casos foram cometidos por mais de um agressor, com maior proporção de vítimas do sexo masculino.
Höing, Jonker e Van Berlo (2010) destacam que os jovens ofensores sexuais de crianças quase sempre agem sozinhos, enquanto os ofensores sexuais de seus pares agem em grupo de $33 \%$ a $50 \%$ dos casos. Os dois tipos de ofensores não apresentaram diferenças significativas em relação ao abuso sexual ou físico no passado e violência entre os pais. No entanto, os adolescentes ofensores de crianças têm significativamente mais problemas de relacionamento com seus pares. As autoras dessa pesquisa apontam que a subdivisão dos ofensores sexuais que agem sozinhos e dos que agem em grupo também é importante para a compreensão do adolescente.

Sobre envolvimento anterior com a justiça, um número significativo de adolescentes $(24,2 \%)$ já tinha um ou mais processos judiciais antes de ser acusado de estupro. Dentre os atos infracionais cometidos estão roubo, furto, lesão corporal, ameaça, dano, estelionato, tráfico e porte de armas, porte e uso de drogas, desacato, homicídio e estupro. Estudos internacionais fazem uma interessante distinção entre adolescentes que cometem exclusivamente ofensa sexual, chamados de sex only, e adolescentes que, além da ofensa sexual, cometem também outros tipos de ofensa de natureza social, sexplus. De acordo com Pullman et al. (2014), os adolescentes ofensores sex plus estão mais envolvidos em fatores antissociais gerais, enquanto os sex only apresentam características distintas, especialmente no que se refere a interesse sexual atípico, como interesse por crianças ou por violência sexual e dificuldades com relacionamentos românticos. Dessa forma, o envolvimento anterior com a justiça também deve ser considerado como um aspecto relevante no direcionamento das intervenções, no acompanhamento clínico e socioeducativo desses jovens.

As vítimas foram prioritariamente do sexo feminino $(67,7 \%)$, o que corrobora os dados do Ministério da Saúde (Brasil, 2018b). Observa-se assim que, desde a adolescência, já são estabelecidas relações de poder dos homens em relação às mulheres, que se convertem em dominação e desigualdade, perdurando até a vida adulta. No entanto, os casos de abuso sexual contra crianças e adolescentes do sexo masculino são bastante representativos (32,3\%). Uma vez que as crenças e estereótipos quanto ao gênero relacionam masculinidade às concepções de força e 
virilidade, identificando os homens como agressores e as mulheres como vítimas, os casos de abuso sexual contra meninos tendem a ser menos reconhecidos e, consequentemente, menos notificados (Brasil, 2018b; Said; Costa, 2019; Vieira, 2017).

Com relação ao tipo de abuso, observa-se uma maior incidência de abusos extrafamiliares $(48,5 \%)$, assim como nos estudos de Domingues e Costa (2017) no Distrito Federal, de Pincolini e Hutz (2014) no Rio Grande do Sul, de Vieira (2017) no Pará, e de Santos et al. (2015) na Bahia, todos com amostras judiciais. Diferentemente de outros estudos nos quais a maior parte dos casos de abuso sexual ocorre no âmbito intrafamiliar (Arpini; Savegnago; Witt, 2017; Martins; Jorge, 2010), ou seja, dentro de casa, por pessoas da família ou que desempenham um papel de responsabilidade ou de cuidador da vítima, bem como por parceiros íntimos (Brasil, 2018b; Domingues; Costa, 2017; Pincolini; Hutz, 2014), observa-se que em relação aos ofensores adolescentes, o sistema de Justiça tem julgado em maior proporção os casos extrafamiliares. Porém, os abusos intrafamiliares não ficam tão distantes (46\%). Ponto relevante em relação a esse aspecto é a dificuldade da denúncia de violência sexual cometida dentro de casa, considerando-se os vínculos familiares existentes (Santos et al., 2015). A violência intrafamiliar tende a ser cometida em um período mais prolongado, com maiores prejuízos para as vítimas, visto que o ofensor geralmente é uma pessoa afetivamente próxima e o convívio é mantido (Arpini; Savegnago; Witt, 2017). Interessante observar ainda que 5,2\% dos abusos ocorreram em instituições de acolhimento (abrigos). Tais situações foram consideradas como abuso institucional (Domingues; Costa, 2017). Porém, vale ressaltar que apesar do adolescente ofensor e da vítima não possuírem laços consanguíneos, ambos vivem na mesma instituição, mantendo convívio e vínculo semelhantes ao familiar.

Sobre a escolha das vítimas, nos casos estudados, a maioria (92,2\%) era conhecida do adolescente, sendo $45,3 \%$ irmãos, sobrinhos e primos, o que comprova que o ofensor sexual é alguém de confiança ou de sua convivência (Brasil, 2018b). Tal fato evidencia a necessidade de estabelecer contextos protetivos, seja para a vítima, como para o ofensor, que pode ter vivido exposto a múltiplas formas de vitimização ou a comportamentos sexualizados por parte dos adultos, inclusive na família (Domingues; Costa, 2017).

Quanto à faixa etária, a pesquisa apontou que as vítimas do sexo feminino tinham, em sua maioria, de 10 a 14 anos $(36,4 \%)$, enquanto as do sexo masculino, de 5 a 9 anos (22,3\%). Resultados semelhantes foram encontrados nas pesquisas de Martins e Jorge (2010) e Platt et al. (2018), porém sem distinção da idade dos ofensores. Tais estudos apontam que o predomínio das vítimas do sexo masculino com pouca idade pode estar relacionado à dificuldade dessas crianças de se defenderem, o que não ocorre com as crianças em idade mais avançada. Observando mais detalhadamente os dados, é possível fazer uma relação entre sexo e idade da vítima e seu vínculo com o ofensor. Por um lado, destaca-se que $26,5 \%$ das vítimas, sendo a maioria do sexo feminino (22,7\%), eram amigas, colegas ou namoradas dos adolescentes ofensores. Por outro, $36,4 \%$ das vítimas do sexo feminino tinham entre 10 e 14 anos. Ao longo do estudo dos processos judiciais, observou-se a presença de relações sexuais em comum acordo com as parceiras, mas com a desaprovação dos pais, que denunciaram o caso às autoridades competentes. Lowenkron (2016), ao discutir menoridade e consentimento sexual, destaca que para o atual e majoritário entendimento da lei, o critério etário (14 anos como a idade do consentimento) é absoluto, ou seja, crianças e adolescentes até 14 anos são considerados incapazes de exercer sua vontade e por isso devem ser protegidos pela lei. No entanto, para a autora, esse critério não pode ser tomado como único e suficiente, uma vez que as categorias baseadas em idade são socialmente construídas e manipuladas, sendo as fronteiras entre o aceitável e o inaceitável constantemente redefinidas e negociadas. Considerar as transformações históricas nas desigualdades de gênero é fundamental nos debates em torno do consentimento no âmbito do comportamento sexual.

Uma importante mudança diz respeito ao abuso sexual entendido como uma violência contra o corpo "íntimo e privado" e não mais como uma ameaça à honra da família. Nesse contexto, além da idade, deve-se analisar um conjunto de fatores, dentre eles o comportamento e personalidade dos sujeitos envolvidos, o tipo de relação e as distâncias sociais entre o "menor" e o "maior", e o contexto em que a relação sexual ocorreu (Lowenkron, 2015). Neste 
estudo, das 291 vítimas, foi possível identificar 47 (16,1\%), todas do sexo feminino, entre 10 e 14 anos, que se declararam namoradas ou que mantiveram relações sexuais "consentidas" com os parceiros. Ainda assim, os adolescentes parceiros foram processados devido, exclusivamente, à faixa etária da vítima. Apesar de a maioria ter recebido remissão ou arquivamento do processo, nove deles foram responsabilizados juridicamente e receberam as medidas socioeducativas de advertência $(n=1)$, prestação de serviço à comunidade $(n=3)$ e liberdade assistida $(n=5)$.

Vale ainda destacar que embora o Código Penal Brasileiro presuma crime qualquer ato sexual com menores de 14 anos de idade, a idade da primeira relação sexual entre os adolescentes tem sido cada vez menor (Gonçalves et al., 2015; Lara; Abdo, 2015). Segundo Gonçalves et al. (2015), a média de idade de início da vida sexual é 14,9 anos, porém uma pesquisa realizada pelos autores mostrou que o início da vida sexual entre 10 e 14 anos tem sido frequente, principalmente entre adolescentes do sexo masculino, com menor escolaridade e com baixo nível econômico. Para Lara e Abdo (2015), vários fatores contribuem para o início da vida sexual precoce, como maior o tempo em casa sem supervisão e sem ocupação, baixa escolaridade, baixo nível socioeconômico e uso de drogas. No âmbito da saúde, a idade da primeira relação entre adolescentes de 10 a 14 anos, acontece num momento da vida no qual o adolescente frequentemente não possui um conjunto de condições, sejam elas emocionais ou de conhecimento, que lhe permita manejar situações que possam trazer consequências a sua saúde no futuro, como adotar sempre boas práticas contraceptivas/preventivas.

\section{Considerações finais}

Os dados da pesquisa reafirmam a pluralidade de perfis dos adolescentes ofensores sexuais, assim como a complexidade dos casos, impossibilitando intervenções padronizadas e descontextualizadas. Além disso, ficou constatada a invisibilidade dos adolescentes ofensores sexuais, devido à falta de estatísticas referentes à violência sexual cometida por eles e à desinformação a respeito de seu contexto sociofamiliar e econômico. Apesar de a população estudada ter recebido uma resposta do sistema de Justiça quanto ao ato praticado, a apuração do ato infracional voltou-se especialmente para as evidências do fato, desconsiderando muitas vezes o contexto do abuso e a trajetória de vida do adolescente.

Oliver (2007) explica que os abusos sexuais cometidos na adolescência possuem conexão direta com tal fase do desenvolvimento, portanto, a ausência de intervenção facilita a reincidência da conduta (Worling; Langton, 2015), o que expressa a necessidade de estudos nessa área. A partir da constatação da complexidade em relação às características dos adolescentes ofensores sexuais, destaca-se a importância dos programas preventivos para se atentarem às características predominantes dos jovens atendidos para que, a partir de tais características, sejam direcionadas intervenções aos múltiplos fatores associados ao abuso sexual. Ronis e Borduin (2007) e Pullman e Seto (2012) defendem os tratamentos multissistêmicos, voltados tanto para os adolescentes como para as famílias. Aspectos como a prática do abuso (se coletivo ou individual), o envolvimento anterior com a justiça, idade da vítima e relação desta com o ofensor, assim como o tipo de abuso (se intrafamiliar ou extrafamiliar) devem ser observados com atenção.

A violência sexual é um fenômeno que possui interface especialmente com as áreas de saúde, assistência social e justiça. A elevada prevalência de violência sexual cometida por adolescentes do ciclo de convivência das vítimas sugere a necessidade de atuação dos diferentes setores sociais e das diversas políticas públicas, visando interromper o ciclo da vitimização/agressão e contribuir para a prevenção da transmissão intergeracional da violência. McGoldrick, Gerson e Petry (2008) ressaltam que existem questões na família que são continuamente repassadas, sendo os padrões de relação das gerações anteriores modelos implícitos para as relações das gerações seguintes. Justamente nesse sentido que se torna fundamental o rompimento da repetição dos padrões de violência na vida familiar que são transmitidos de uma geração a outra.

Observa-se ainda que os adolescentes ofensores sexuais julgados pelo sistema de Justiça representam a parte da população excluída socialmente. São jovens com baixa escolaridade, de famílias com baixa renda e com dificuldade de acesso aos serviços de 
proteção social. Também com relação à violência sexual, o ônus da responsabilização tem recaído sobre a população mais pobre, na qual a Justiça se mantém seletiva frente a uma sociedade que é marcada pela desigualdade social, de gênero e raça/ etnia (Bonalume; Jacinto, 2019).

Por fim, ressaltam-se as limitações metodológicas desta pesquisa, relacionadas principalmente ao registro das informações. Além da escassez de informações em relação ao adolescente acusado, estas, quando existentes, estavam registradas em diferentes etapas do processo judicial. Tendo em vista o longo prazo para a apuração do ato infracional, que pode durar poucos dias ou mais de três anos, as informações sobre escolaridade e condições familiares não foram registradas no mesmo momento para todos os casos. Em alguns processos, tais dados estavam no próprio boletim de ocorrência, em outros, nas atas das audiências ou em relatórios específicos. Essas dificuldades muitas vezes estão relacionadas ao constrangimento e sofrimento vivenciado por esses sujeitos, que não conseguem falar sobre o que aconteceu, dificultando o registro por parte do sistema de Justiça ao longo da tramitação do processo. Porém, a dificuldade de registros das informações não inviabilizou a análise e interpretação, mantendo a importância deste estudo.

\section{Referências}

ARPINI, D. M.; SAVEGNAGO, S. D. O.; WITT, C. S. $O$ ponto de vista de adolescentes em situação de vulnerabilidade social sobre o agressor sexual. Pesquisas e Práticas Psicossociais, São João delRei, v. 12, n. 2, p. 247-262, 2017.

BARROSO, R. N. S. G. Características e especificidades de jovens agressores sexuais. 2012. Tese (Doutorado em Psicologia) Universidade de Aveiro, Portugal, 2012.

BONALUME, B. C.; JACINTO, A. G. Encarceramento juvenil: o legado histórico de seletividade e criminalização da pobreza. Revista Katálysis, Florianópolis, v. 22, n. 1, p. 16o-170, 2019.

BRASIL. Lei n 8.069 , de 13 de julho de 1990. Dispõe sobre o Estatuto da Criança e do Adolescente e dá outras providências. Diário Oficial da União, Brasília, DF, 16 jul. 199o. Disponível em: <https://bit.ly/3qirılC>. Acesso em: 2 out. 2018.

BRASIL. Lei n ${ }^{0}$ 12.015, de 7 de agosto de 2009. Altera o título VI da parte especial do DecretoLei ${ }^{0}$ 2.848, de 7 de dezembro de 1940 (Código Penal) e dá outras providências. Diário Oficial da União, Brasília, DF, 10 ago. 2009. Disponível em: <https://bit.ly/3od5VY5>. Acesso em: 2 out. 2018.

BRASIL. Lei $\mathrm{n}^{0} 13 \cdot 718$, de 24 de setembro de 2018. Altera o Decreto-Lei ${ }^{0}$ 2.848, de 7 de dezembro de 1940 (Código Penal), e dá outras providências. Diário Oficinal da União, Brasília, DF, 25 set. 2018a. Disponível em: <https://bit.ly/2OrEXsU>. Acesso em: 2 out. 2018.

BRASIL. Ministério da Saúde. Análise epidemiológica da violência sexual contra crianças e adolescentes no Brasil, 2011 a 2017. Boletim Epidemiológico, Brasília, DF, v. 49, n. 27, 2018b. Disponível em: <https://bit.ly/3kI9G1a>. Acesso em: 2 out. 2018.

CALE, J. et al. Offense trajectories, the unfolding of sexual and non-sexual criminal activity, and sex offense characteristics of adolescent sex offenders. Sexual Abuse, Thousand Oaks, v. 28, n. 8, p. 791-812, 2015.

CARRETEIRO, T. C. O. Adolescências e experimentações possíveis. In: MARRA, M. M.; COSTA, L. F. (Org.). Temas da clínica do adolescente e da família. São Paulo: Ágora, 2010. p. 15-24.

Costa, B. N. S.; COSTA, L. F. Perpetrador e vítima: o adolescente que cometeu ofensa sexual. Revista Latinoamericana de Ciencias Sociales, Niñez y Juventud, Manizales, v. 11, n. 2, p. 633-645, 2013.

COSTA, L. F.; SANTOS, V. A. A natureza paradoxal das medidas protetivas em casos de violência sexual intrafamiliar. Revista de Direito da Infância e da Juventude, São Paulo, v. 1, n.1, p. 281-30o, 2013.

COSTA, L. F. et al. As relações familiares do adolescente ofensor sexual. Psico-USF, Itatiba, v. 18, n. 1, p. 33-44, 2013.

DOMINGUES, D. F.; COSTA, L. F. Adolescentes que cometeram ofensa sexual: análise documental 
em processos judiciais. Pensando Famílias, Porto Alegre, v. 21, n. 2, p. 15-27, 2017.

DRIEMEYER, W.; YOON, D.; BRIKEN, P. Sexuality, antisocial behavior, aggressiveness, and victimization in juvenile sexual offenders: a literature review. Sexual Offender Treatment, Lengerich, v. 6, n. 1, 2011.

GONÇALVES, H. et al. Início da vida sexual entre adolescentes (10 a 14 anos) e comportamentos em saúde. Revista Brasileira de Epidemiologia, São Paulo, v. 18, n. 1, p. 1-18, 2015. Disponível em: <https://bit.ly/387eZSv>. Acesso em: 21 out. 2018.

HÖING, M.; JONKER, M.; VAN BERLO, W. T. M. Juvenile sex offenders in a Dutch mandatory educational programme: subtypes and characteristics. Journal of Sexual Aggression, London, v. 16, n. 3, p. 332-346, 2010.

IPEA - INSTITUTO DE PESQUISA ECONÔMICA APLICADA. Atlas da violência. Rio de Janeiro, 2018. Disponível em: <https://bit.ly/3sUPpIF>. Acesso em: 4 mar. 2021.

KRELL, O. J. G.; AMADOR, C. C. S. O abuso sexual intrafamiliar: propostas para uma proteção jurídicoadministrativa mais efetiva de crianças e adolescentes. Revista Eletrônica do Mestrado em Direito da Ufal, Maceió, v. 6, n. 3, p. 94-106, 2015. Disponível em: <https://bit.ly/38an5tY>. Acesso em: 4 mar. 2021.

LARA, L. A. S.; ABDO, C. H. N. Aspectos da atividade sexual precoce. Revista Brasileira de Ginecologia e Obstetrícia, Rio de Janeiro, v. 37, n. 5, p. 199-202, 2015.

LOWENKRON, L. Consentimento e vulnerabilidade: alguns cruzamentos entre o abuso sexual infantil e o tráfico de pessoas para fim de exploração sexual. Cadernos Pagu, Campinas, n. 45, p. 225-258, 2015.

LOWENKRON, L. Menina ou moça? Menoridade e consentimento sexual. Desidades, Rio de Janeiro, v. 4, n. 10, p. 9-18, 2016.

MARTINS, C. B. G.; JORGE, M. P. M. Abuso sexual na infância e adolescência: perfil das vítimas e agressores em município do Sul do Brasil. Texto \& Contexto Enfermagem, Florianópolis, v. 19, n. 2, p. 246-255, 2010.

MCCUISH, E. C.; LUSSIER, P.; CORRADO, R. R. Examining antisocial behavioral antecedents of juvenile sexual offenders and juvenile non-sexual offenders. Sexual Abuse, Thousand Oaks, v. 27 , n. 4, p. 414-438, 2014.

MCGOLDRICK, M.; GERSON, R.; PETRY, S. Genogramas: avaliação e intervenção familiar. Porto Alegre: Artmed, 2008.

OLIVER, B. E. Three steps to reducing child molestation by adolescents. Child Abuse \& Neglect, Oxford, v. 31, n. 7, p. 683-689, 2007. Disponível em: <https://bit.ly/3sNHTPE>. Acesso em: 4 mar. 2021.

PENSO, M. A. et al. Jovens pedem socorro: o adolescente que praticou ato infracional e o adolescente que cometeu ofensa sexual. Brasília, DF: Liber Livro, 2012.

PINCOLINI, A. M. F.; HUTZ, C. S. Abusadores sexuais adultos e adolescentes no sul do Brasil: pesquisa em denúncias e sentenças judiciais. Temas em Psicologia, Ribeirão Preto, v. 22, n. 2, p. 301-311, 2014.

PLATT, V. B. et al. Violência sexual contra crianças: autores, vítimas e consequências. Ciência \& Saúde Coletiva, Rio de Janeiro, v. 23, n. 4, p. 1019-1031, 2018.

PULLMAN, L. E.; SETO, M. C. Assessment and treatment of adolescent sexual offenders: implications of recent research on generalist versus specialist explanations. Child Abuse \& Neglect, Oxford, v. 36, n. 3, p. 203-209, 2012.

PULLMAN, L. E. et al. Examining the developmental trajectories of adolescent sexual offenders. Child Abuse \& Neglect, Oxford, v. 38, n. 7, p. 1249-1258, 2014.

RONIS, S. T.; BORDUIN, C. M. Individual, family, peer, and academic characteristics of male juvenile 
sexual offenders. Journal of Abnormal Child

Psychology, New York, v. 35, n. 2, p. 153-163, 2007.

SAID, A. P.; COSTA, L. F. Family dynamics of boys victims of sexual abuse. Paidéia, Ribeirão Preto, v. 29, e2908, 2019.

SANTOS, C. A. et al. Agressor sexual de crianças e adolescentes: análise de situações relacionadas à violação e vítimas. Adolescência \& Saúde, Rio de Janeiro, v. 12, n. 3, p. 7-20, 2015.
VIEIRA, V. C. Perfil dos adolescentes acusados de ofensores sexuais de crianças e adolescentes. 2017. Dissertação (Mestrado em Criminologia Universidade Fernando Pessoa, Porto, 2017. WORLING, J.; LANGTON, C. M. A prospective investigation of factors that predict desistence from recidivism for adolescents who have sexually offended. Sexual Abuse, Thousand Oaks, v. 27, n. 1, p. 127-142, 2015.

\section{Contribuição dos autores}

Eusébio, Pereira e Silva coletaram e tabularam os dados. Bastos coletou os dados e redigiu o artigo. Costa revisou o manuscrito $e$ aprovou a versão final a ser publicada.

Recebido: $11 / 03 / 2019$

Reapresentado: 03/06/2020

Aprovado: 09/09/2020 